\title{
Properties of Natural Rubber-Based Composites Containing Fullerene
}

\author{
Omar A. Al-Hartomy, ${ }^{1,2}$ Ahmed A. Al-Ghamdi, ${ }^{1}$ Falleh Al-Salamy, ${ }^{1,3}$ Nikolay Dishovsky, ${ }^{4}$ \\ Desislava Slavcheva, ${ }^{4}$ and Farid El-Tantawy ${ }^{5}$ \\ ${ }^{1}$ Department of Physics, Faculty of Science, King Abdulaziz University, Jeddah 21589, Saudi Arabia \\ ${ }^{2}$ Department of Physics, Faculty of Science, University of Tabuk, Tabuk 71491, Saudi Arabia \\ ${ }^{3}$ Department of Mathematics, Faculty of Science, University of Tabuk, Tabuk 71491, Saudi Arabia \\ ${ }^{4}$ Department of Polymer Engineering, University of Chemical Technology and Metallurgy, 8 Kl. Ohridski Boule vard., \\ 1756 Sofia, Bulgaria \\ ${ }^{5}$ Department of Physics, Faculty of Science, Suez Canal University, Ismailia 41522, Egypt
}

Correspondence should be addressed to Nikolay Dishovsky, dishov@uctm.edu

Received 9 March 2012; Revised 3 June 2012; Accepted 17 October 2012

Academic Editor: Qinmin Pan

Copyright (C) 2012 Omar A. Al-Hartomy et al. This is an open access article distributed under the Creative Commons Attribution License, which permits unrestricted use, distribution, and reproduction in any medium, provided the original work is properly cited.

In this study the influence of fullerenes in concentrations from 0.5 to $1.5 \mathrm{phr}$ on both the vulcanization characteristics of the compounds and physicomechanical, dynamic, and dielectric properties and thermal aging resistance of nanocomposites on the basis of natural rubber has been investigated. The effect of the filler dispersion in the elastomeric matrix has been also investigated. Neat fullerene and the composites comprising it have been studied and characterized by scanning electron microscopy (SEM) and transmission electron microscopy (TEM).

\section{Introduction}

Harold W. Kroto, Robert F. Curl, and Richard E. Smalley won the Nobel Prize for chemistry in 1996 for having discovered in 1985 a new allotrope of carbon in which the atoms are arranged in closed shells. The new form was found to have the structure of truncated icosahedrons and was named Buckminsterfullerene after the architect Buckminster Fuller who designed geodesic domes in the 1960's.

Unlike the other allotropes of carbon-graphite and diamond-which are voluminous materials possessing the properties of three-dimensional crystals, fullerenes are hollow molecules composed of carbon in the $\mathrm{sp}^{2}$ hybrid state of the valence electrons. Fullerene has a number of properties differing them from the other forms of carbon, namely, superconductivity $[1,2]$, low thermal conductivity $[1,2]$, and hardness higher than that of diamond in the crystal state [3].

The most important representative of fullerene is $\mathrm{C}_{60}$. It consists of molecular balls made of 60 or more carbon atom clusters linked together $[1,2]$. Each carbon atom is bonded to other carbon atoms by two single bonds and by one double bond. This causes $\mathrm{C}_{60}$ to act more like a "superalkene" than as a "superaromatic." [4]. The structure, properties, and the applications of fullerenes were described thoroughly in [5]. One perspective application is to use fullerene as ingredient in rubber blends and rubber-based composites in order to achieve enhanced durability, lower heat-built up, and better fuel economy [5]. A method of using fullerenes to enhance the properties of rubber composites is proposed by Chow [6].

Jurkowska et al. report on their studies on the properties of composites based on natural rubber (NR) when using fullerene in the $0.065 \sim 0.75 \mathrm{phr}$ concentration range [7]. Noteworthy is the fact that the fullerene is introduced into the composition of the rubber compound together with carbon black. The total amount of the filler is $5 \mathrm{phr}$. It has been found that the addition of fullerene at a concentration between 0.065 and $0.75 \mathrm{phr}$ increases Schob elasticity, hardness, and modulus of NR-based rubber. There 
is no substantial influence of fullerene on $T_{g}, \tan \delta$, and $G$-modulus; all evaluated by dynamic mechanical thermal analysis (DMTA) at twisting within a temperature range -150 to $-50^{\circ} \mathrm{C}$ (glassy state). At temperatures between 0 and $150^{\circ} \mathrm{C}$ (rubbery state) an increase in modulus and some changes in the slope of segments in $G(T)$ curves have been observed [7]. We presupposed that a higher fullerene concentration could cause another improvement in the composites properties which has not been studied, and there are no literature data. We decided to add fullerene to the rubber blend without carbon black or other fillers, so that we could trace the changes caused by pure fullerene and compare the properties of the composites comprising it and those of a fullerene-free one.

The development of new materials based on the unique properties exhibited by the family of fullerenes keeps on attracting a great interest from materials scientists. The progress of the recent studies discloses new properties of fullerene containing nanocomposites, but very often these are polymer composites based on polyethylene, polystyrene, polyurethane, and so forth [8-10].

This paper presents the investigations on how neat fullerene added in the powder form up to $1.5 \mathrm{phr}$ to natural rubber-based composites affects their properties. The studies covered the fullerene influence on both the vulcanization characteristics of the compounds and a number of properties of the composites thus prepared: physicomechanical, dynamic - by DMTA, dielectric - by dielectric thermal analysis (DETA), and thermal aging resistance. The effect of the filler dispersion in the elastomeric matrix has been also investigated. Neat fullerene and the composites comprising it have been studied and characterized by scanning electron microscopy (SEM) and transmission electron microscopy (TEM).

\section{Experimental}

2.1. Materials. Natural rubber-SMR 10 was purchased from North Special Rubber Corporation of Hengshui, Hebei Province, China.

Other ingredients such as zinc oxide $(\mathrm{ZnO})$, stearic acid (SA), N-tert-Butyl-2-benzothiazolesulfenamide (TBBS), and sulphur $(\mathrm{S})$ were commercial grades and used without further purification.

2.2. Characterization of the Fullerene Used. The investigations reported in this paper were on neat fullerene powder comprising $99.5 \% C_{60}$ fullerene produced by Alfa Aesar (Johnson Matthey Company). Fullerene density was $1.65 \mathrm{~g} / \mathrm{cm}^{3}$. The micrograph in Figure 1 and the $50 \mathrm{~nm}$ marker on it show the fullerene particles to be aggregates of several $\mathrm{nm}$ in size, for example, $300 \mathrm{~nm}$ wide and $700 \mathrm{~nm}$ long, composed of initial particles about 50-60 nm large. The micrograph taken in an electron diffraction regime (Figure 1(b)) of the aggregate in Figure 1(a) shows its having a crystal structure as the initial fullerene particles do. There are both point reflections characteristic of the monocrystal structures and rings characteristic of polycrystal formations.
2.3. Sample Preparation and Vulcanization. A rubber compound was taken as a reference, and five compounds with different amounts of fullerene powder were prepared on an open two-roll laboratory mill $(\mathrm{L} / \mathrm{D} 320 \times 360$ and friction 1.27). The speed of the slow roll was $25 \mathrm{rpm}$. The formulations of the compounds prepared are shown in Table 1. The compounding was carried out as follows: the raw rubber was loaded into the mill, and $\mathrm{ZnO}_{2}$ and stearic acid were added after $5 \mathrm{~min}$. After $3 \mathrm{~min}$ of homogenization the fullerene was added. Following another homogenization for $7 \mathrm{~min}$ the accelerator and sulfur were added, and the compound was rehomogenized for $4 \mathrm{~min}$. The process of preparing the rubber compound took $19 \mathrm{~min}$. The temperature of the rolls did not exceed $70^{\circ} \mathrm{C}$. The experiments were repeated for verifying the statistical significance. The ready compounds in the form of sheets stayed 24 hours prior to their vulcanization.

The optimal vulcanization time was determined by the vulcanization isotherms taken on an oscillating disc vulcameter MDR 2000 (Alpha Technologies) at $150^{\circ} \mathrm{C}$, according to ISO 3417:2002. The vulcanization was performed on an electric hydraulic press at $10 \mathrm{MPa}$. Specimens of $200 \times$ $200 \times 2 \mathrm{~mm}$ were cut from the samples prepared and used for further investigations.

\subsection{Measurements}

2.4.1. Vulcanization Characteristics. Vulcanization characteristics $\left(M_{L}\right.$ : minimum torque, $\mathrm{dN} \cdot \mathrm{m} ; M_{H}$ : maximum torque, $\mathrm{dN} \cdot \mathrm{m}, \Delta M=M_{H}-M_{L}$, $t_{s 2}$ : scorching time, min; $T_{90}$ : optimum vulcanization time, min) were determined on the basis of the vulcanization isotherms taken on an oscillating disc vulcameter MDR.

2.4.2. Dynamic Mechanical Thermal Analysis (DMTA). Dynamic properties (storage modulus $\left(E^{\prime}\right)$ and mechanical loss angle tangent $(\tan \delta)$ ) of the studied vulcanizates 2000 (Alpha Technologies) at $150^{\circ} \mathrm{C}$, according to ISO $3417: 2002$, were investigated using a dynamic mechanical thermal analyzer Mk III system (rheometric scientific). The data were obtained at $5 \mathrm{~Hz}$ frequency and strain amplitude $64 \mu \mathrm{m}$ in the $-80^{\circ} \mathrm{C}$ to $80^{\circ} \mathrm{C}$ range using a heating rate of $3^{\circ} \mathrm{C} / \mathrm{min}$ under single cantilever bending mode. The dimensions of the investigated samples were as follows: width $10 \mathrm{~mm}$ and length $25 \mathrm{~mm}$. The thickness of each sample was measured using a micrometer and was about $2.0-2.1 \mathrm{~mm}$.

2.4.3. Dielectric Thermal Analysis. The dielectric properties are used to characterize the relaxation behavior of the materials. Materials possess a dielectric constant $\left(\varepsilon^{\prime}\right)$ characterizing the extent of electrical polarization which can be induced in the material by an electrical field. If an alternating electrical field is applied, the polarization lags behind the field by a phase angle $\delta$. This results in partial dissipation of the stored energy. The dissipated energy is proportional to the dielectric loss $\left(\varepsilon^{\prime \prime}\right)$ and the stored energy to the dielectric constant $\left(\varepsilon^{\prime}\right) . \varepsilon^{\prime \prime}$ and $\varepsilon^{\prime}$ are measured by Dielectric Thermal Analyzer (DETA) and the ratio of $\varepsilon^{\prime \prime} / \mathcal{\varepsilon}^{\prime}=\tan \delta$. 


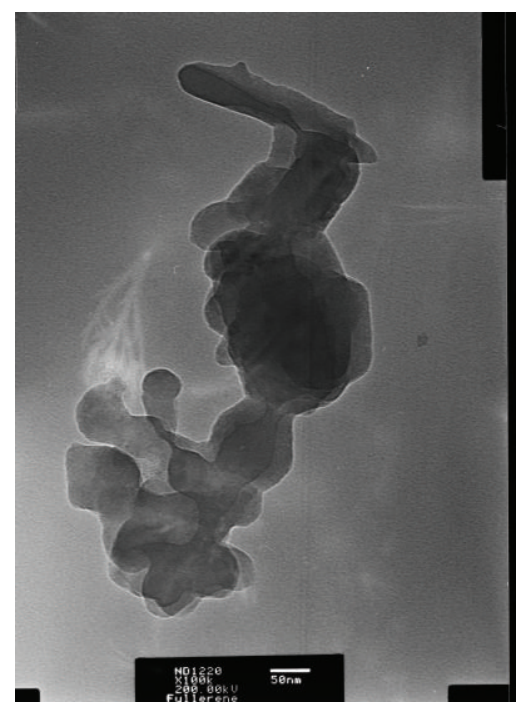

(a)

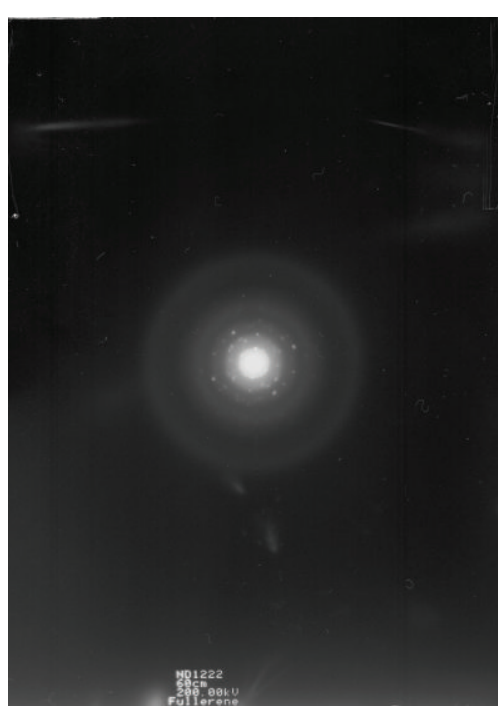

(b)

FIGURE 1: Micrographs of fullerene aggregates in transmission regime (a) and selected area of electron diffraction regime (b).

TABLE 1: Compositions of the NR-based rubber compounds.

\begin{tabular}{|c|c|c|c|c|c|c|}
\hline & NR1 & NR2 & NR3 & NR4 & NR5 & NR6 \\
\hline Natural rubber SMR 10 & 100 & 100 & 100 & 100 & 100 & 100 \\
\hline Zinc oxide & 5 & 5 & 5 & 5 & 5 & 5 \\
\hline Stearic acid & 2 & 2 & 2 & 2 & 2 & 2 \\
\hline Fullerene powder & 0 & 0.5 & 0.75 & 1.0 & 1.25 & 1.5 \\
\hline TBBS* & 0.8 & 0.8 & 0.8 & 0.8 & 0.8 & 0.8 \\
\hline Sulphur & 2.25 & 2.25 & 2.25 & 2.25 & 2.25 & 2.25 \\
\hline
\end{tabular}

* TBBS: N-tert-Butyl-2-benzothiazolesulfenamide.

Dielectric properties (permittivity $\left(\varepsilon^{\prime}\right)$ and dielectric loss angle tangent $($ DETA $\tan \delta)$ ) were investigated using a Dielectric thermal analyzer (rheometric scientific) at 4 different frequencies $(1 \mathrm{kHz}, 10 \mathrm{kHz}, 100 \mathrm{kHz}$ and $1 \mathrm{MHz})$ and temperature $30^{\circ} \mathrm{C}$ and $90^{\circ} \mathrm{C}$ on a sample having a diameter approximately $32 \mathrm{~mm}$ and $1 \mathrm{~mm}$ thickness.

2.4.4. Tensile Elastic Properties of the Vulcanizates. The tensile-elastic properties $\left(M_{100}\right.$ and $M_{300}$ : modules at $100 \%$ and $300 \%$ of elongation, resp., $\mathrm{MPa} \sigma$ : tensile strength, $\mathrm{MPa}$; $\varepsilon_{r}$ : relative elongation at break,\%) of the vulcanizates studied were determined according to ISO 37:2002.

Shore A Hardness. Shore A hardness was determined according to ISO 7619:2001.

Thermal Aging Resistance. The thermal aging resistance was tested according to ISO 188:2002. The aging was carried out in an air circulating camera at $70^{\circ} \mathrm{C}$ for $72 \mathrm{~h}$.

SEM and TEM Micrographs. The composite morphology was investigated by scanning electron microscopy (SEM) micrographs taken on a JEOL JSM-5510.
The particle size, size distribution of the filler, and microstructure of the composites were determined using a transmission electron microscope (TEM) JEOL 2100 at accelerating voltage $200 \mathrm{kV}$. The specimens were prepared by grinding the samples in an agate mortar and dispersing them in methanol by ultrasonic treatment for $6 \mathrm{~min}$. A droplet of the suspension was dripped on standard carbon films on $\mathrm{Cu}$ grids. Additional data for the crystal structure were obtained using selected area electron diffraction (SAED) method.

\section{Results and Discussion}

3.1. Dispersion of the Fullerene Powder in the Rubber Matrix. One of the primary purposes of the mixing process for rubber compounds is the distribution and disagglomeration, often called dispersion, of reinforcing fillers. It is a wellknown fact that the dispersion of the filler has great effect on the properties of the obtained vulcanizates [11]. On the other hand, the increasing filler dispersion increases its relative surface and surface energy. Occurrence of an agglomeration has been observed in the case of the smaller particles which hinders the homogenization during the compounding. It has been established that the mixing begins with the formation of the so-called "soft" agglomerates which are further broken 


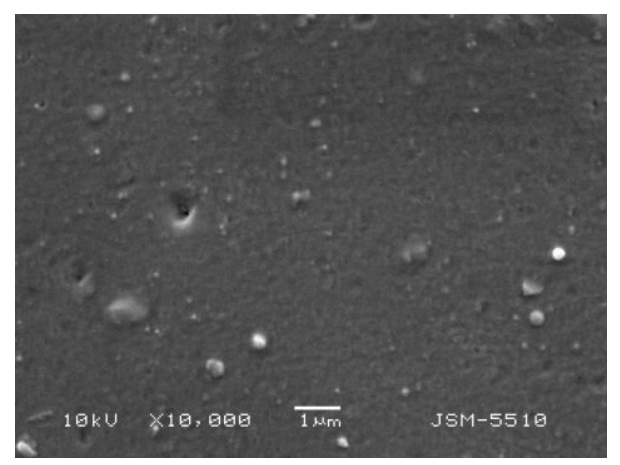

(a)

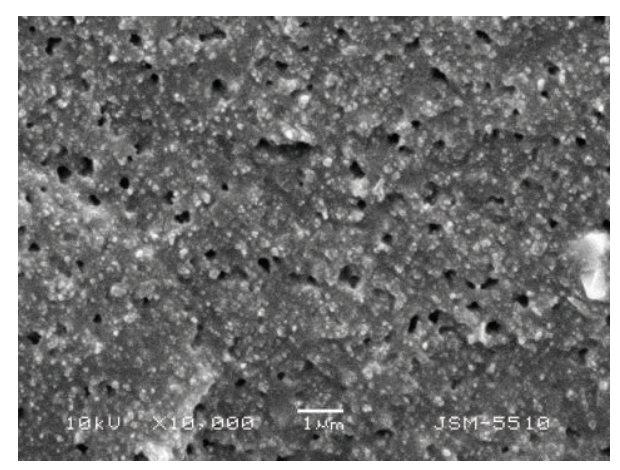

(b)

FIGURE 2: SEM micrograph of a non-unfilled composite (a) and a composite, containing $1.5 \mathrm{phr}$ of fullerene (b).

down into pieces and dispersed [12]. With a shorter cycle of mixing these originally formed agglomerates worsen the mechanical properties because of the bigger size of the particles. The agglomeration is probably the most important aspect of dispersion [13], because of the detrimental effects of microflaws on properties such as tensile strength, abrasion resistance, and fatigue life. We used SEM and TEM to investigate the fullerene aggregates and their dispersion. SEM reveals the morphology, while TEM gives information on the structure of the composites studied.

Figures 2 and 3 present the SEM and TEM images of the composites.

The difference between the filled and nonfilled composites is obvious. Fullerene particles are pronounced and well distinguishable from the particles of the other composite ingredients, for example, $\mathrm{ZnO}_{2}$ ones. However, SEM resolution is not enough to visualize the structure of filler particles, but it is seen that their size is in the $0.1-0.2 \mu \mathrm{m}$ range. Although SEM is useful to observe different morphologies of fracture and failure surface as well as the fillers aggregates on this surface, it should be noted that it is not suitable to observe the homogeneous dispersion of the filler.

The micrographs in Figure 3 show a relatively even distribution of the filler particles in the elastomeric matrix which is marked by a satisfactory homogeneity. However, the particles shown on Figure 1 have undergone an additional disagglomeration during the compounding, and their size thus decreases to $40-50 \mathrm{~nm}$. The SAED micrograph confirms their crystal structure typical for fullerenes.

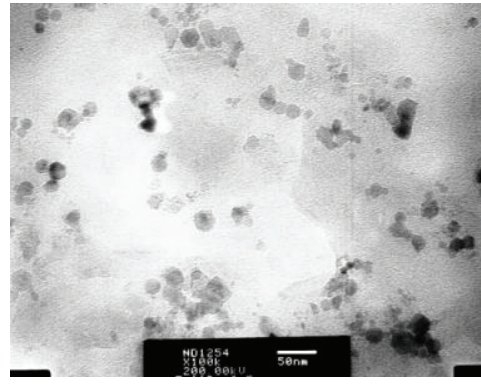

(a)

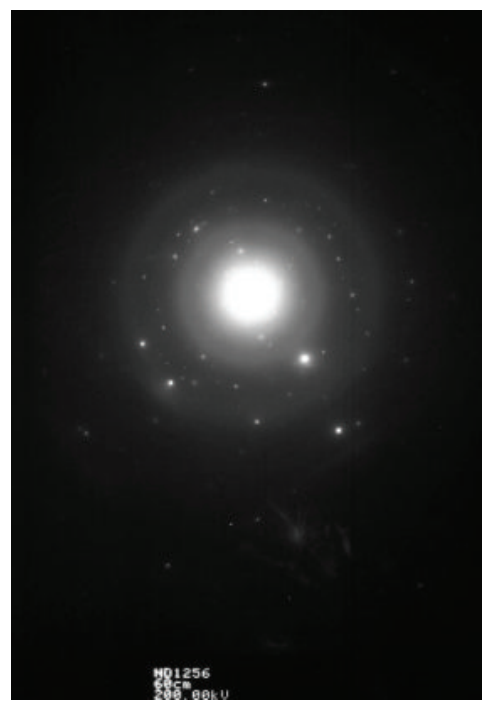

(b)

FIGURE 3: TEM micrograph of composites containing $1.5 \mathrm{phr}$ of fullerene (a) and a selected area electron diffraction (SAED) micrograph (b).

3.2. Vulcanization Characteristics. The main vulcanization characteristics of the samples determined from the isotherms are presented in Table 2.

As seen from Table 2 the increasing amount of fullerene affects in a different manner the vulcanization characteristics of the fullerene containing composites: the minimum torque revealing the viscosity of the rubber compound increases negligibly, while the maximum torque and $\Delta M$ revealing the hardness and density of the vulcanization crosslinks decrease. Obviously, the induction vulcanization period meant by $t_{s 2}$ and the optimal vulcanization time $T_{90}$ increases with the increasing fullerene amount. The results show that despite of its small amount fullerene retards the vulcanization process to a certain extent. That is definitely due to fullerene being a strong acceptor of radicals, while the accelerated sulfur vulcanization in the presence of stearic acid and $\mathrm{ZnO}_{2}$ as an activator runs as a process of radical type, according to the modern notions [14] of its mechanism.

3.3. Physicomechanical Parameters. Table 3 systemizes the main physicomechanical parameters of the NR-based composites comprising different amounts of fullerene. 
TABLE 2: Vulcanization characteristics of the rubber compounds investigated.

\begin{tabular}{lcccccc}
\hline & NR1 & NR2 & NR3 & NR4 & NR5 & NR6 \\
\hline$M_{L}, \mathrm{dNm}$ & 0.15 & 0.11 & 0.15 & 0.20 & 0.20 & 0.22 \\
$M_{H}, \mathrm{dNm}$ & 9.90 & 9.86 & 9.35 & 9.15 & 9.00 & 8.92 \\
$\Delta M=M_{H}-M_{L}$ & 9.75 & 9.75 & 9.20 & 8.95 & 8.80 & 8.70 \\
$t_{\mathrm{s} 2}$, min:s & $4: 21$ & $4: 24$ & $4: 27$ & $4: 30$ & $4: 35$ & $4: 39$ \\
$T_{90}$, min:s & $8: 02$ & $8: 33$ & $8: 50$ & $9: 13$ & $9: 20$ & $9: 25$ \\
\hline
\end{tabular}

TAble 3: Physicomechanical parameters of composites comprising fullerene.

\begin{tabular}{lcccccc}
\hline & NR1 & NR2 & NR3 & NR4 & NR5 & NR6 \\
\hline$M_{100}, \mathrm{MPa}$ & 0.80 & 0.90 & 0.95 & 1.0 & 1.5 & 1.9 \\
$M_{300}, \mathrm{MPa}$ & 2.7 & 2.9 & 3.0 & 3.3 & 3.7 & 3.9 \\
$\sigma, \mathrm{MPa}$ & 17.7 & 14.8 & 15.4 & 16.3 & 16.5 & 17.3 \\
$\boldsymbol{\varepsilon}_{r}, \%$ & 740 & 780 & 770 & 760 & 755 & 740 \\
Shore A hardness & 50 & 52 & 52 & 53 & 54 & 55 \\
\hline
\end{tabular}

TABLE 4: Aging coefficients of composites comprising fullerene.

\begin{tabular}{lcccccc}
\hline & NR1 & NR2 & NR3 & NR4 & NR5 & NR6 \\
\hline$M_{100}, \mathrm{MPa}$ & 37.0 & 20.5 & 15.7 & 12.5 & 11.0 & 10 \\
$M_{300}, \mathrm{MPa}$ & 37 & 25 & 23 & 21.7 & 17 & 11.7 \\
$\sigma, \mathrm{MPa}$ & -10 & -5 & -5 & -3 & -3 & -0.5 \\
$\varepsilon_{r}, \%$ & -19 & -15 & -14 & -14 & -12 & -10 \\
Shore A hardness & +3 & +2 & +2 & +1 & +1 & +1 \\
\hline
\end{tabular}

The general impression from the results in Table 3 is that adding of $0,5 \sim 1,5 \mathrm{phr}$ fullerene to the natural rubber matrix does not lead to improvement of the physicomechanical parameters of composites. The filler quantity is very small to reveal its reinforcing effect, and moreover, this small quantity causes difficulties to be distributed uniformly in the rubber matrix. The arising inhomogeneity is may be the reason for inadequate properties of the composites. There is a positive tendency as regard to Shore $\mathrm{A}$ hardness because the fullerene's hardness is higher. Modules of elongation $M_{100}$ and $M_{300}$ increase gradually with the increasing fullerene amount.

Natural rubber is crystallizing rubber, and the fillers quantity exerts influence on the size of spherulites, the main crystal formations in it. When the filler quantity increases their size becomes smaller, respectively, they have few defects and as a result the tensile strength increases and the relative elongation decreases. The decrease of the relative elongation probably is due to the decreased ability of the macromolecules to become deformed along the direction of the deformation effort.

The obtained values of the physicomechanical parameters seem lower than the expected for NR-based vulcanizates. However, the data show that those values are not much different from the values for NR-based vulcanizates filled with fullerene reported by other authors [7].

Table 4 presents the aging coefficients with regard to the most important physicomechanical parameters of composites comprising fullerene.
As seen from the results presented in Table 4 the increasing fullerene amount improves gradually the thermal aging resistance of the vulcanizates. Such effects have been observed even at low fullerene concentrations [7].

The noninhibited oxidation of the elastomers is considered to be a radical degenerated branching chain process [15] which could be schematically described as follows (RH stands for the elastomer).

(1) Initiation formation of radical factors under the effect of heat, light, and so forth:

$$
\mathrm{R}^{*}, \mathrm{RO}^{*}, \mathrm{ROO}^{*}
$$

(2) Chain growth according the schemes:

$$
\begin{gathered}
\mathrm{R}^{*}+\mathrm{O}_{2} \Longrightarrow \mathrm{ROO}^{*} \\
\mathrm{ROO}^{*}+\mathrm{RH} \Longrightarrow \mathrm{ROOH}+\mathrm{R}^{*}
\end{gathered}
$$

(3) Chain branching:

$$
\begin{gathered}
\mathrm{ROOH} \Longrightarrow \mathrm{RO}^{*}+\mathrm{HO}^{*} \\
\mathrm{RO}^{*}+\mathrm{RH} \Longrightarrow \mathrm{ROH}+\mathrm{R}^{*} \\
\mathrm{HO}^{*}+\mathrm{RH} \Longrightarrow \mathrm{HOH}+\mathrm{R}^{*}
\end{gathered}
$$




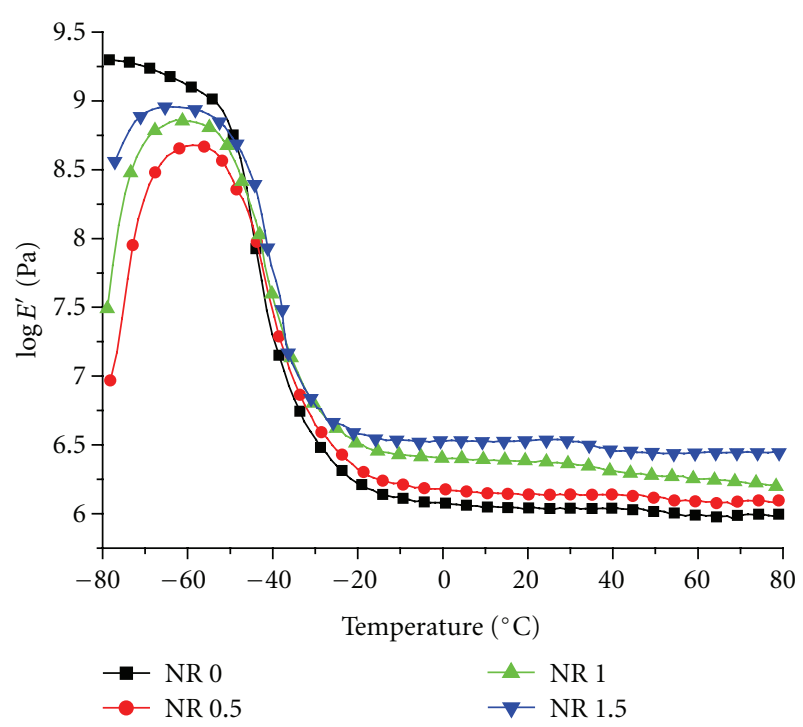

Figure 4: Dependence of storage modulus on temperature and on the amount of filler introduced.

(4) Oxidative chain scission: it is a transformation of the above radicals into inactive products. The fullerene comprised by the composite participates in an accelerated reaction with the free radicals and causes a scission of the oxidative chain:

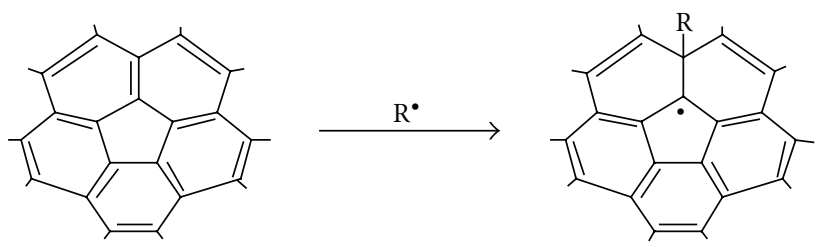

According to the mechanism described fullerene turns into a powerful antioxidant.

3.4. Dynamic Properties of the Studied Vulcanizates. The dependences of the storage modulus and mechanical loss angle tangent on the filler amount studied in the range from $-80^{\circ} \mathrm{C}$ to $+80^{\circ} \mathrm{C}$ are presented in Figures 4 and 5 .

As Figure 4 shows, all composites studied are in the glassy state in the $-80^{\circ} \mathrm{C} \sim-50^{\circ} \mathrm{C}$ range. After the transition from the glassy state into the high-elastic state, occurring at about $-50^{\circ} \mathrm{C}$, the storage modulus starts to decrease. It decreases till $-20^{\circ} \mathrm{C}$, and after that in the $-20^{\circ} \mathrm{C} \sim 80^{\circ} \mathrm{C}$ range practically it does not depend on the temperature. A tendency of a slight increase in the storage modulus with the increasing fullerene amount has been observed in the $-80^{\circ} \mathrm{C} \sim-50^{\circ} \mathrm{C}$ range. The increase is more pronounced in the $-20^{\circ} \mathrm{C} \sim+80^{\circ} \mathrm{C}$ range. In literature this fact is most often related to the formation of strong bonds between the rubber macromolecules and to the formation of a tridimensional network $[4,7,16]$.

The mechanical loss angle tangent which is the relation between the dynamic loss modulus $\left(E^{\prime \prime}\right)$ and storage modulus $\left(E^{\prime}\right)$ reveals the mobility of the macromolecules as well as the phase transitions occurring in the polymers. Figure 5

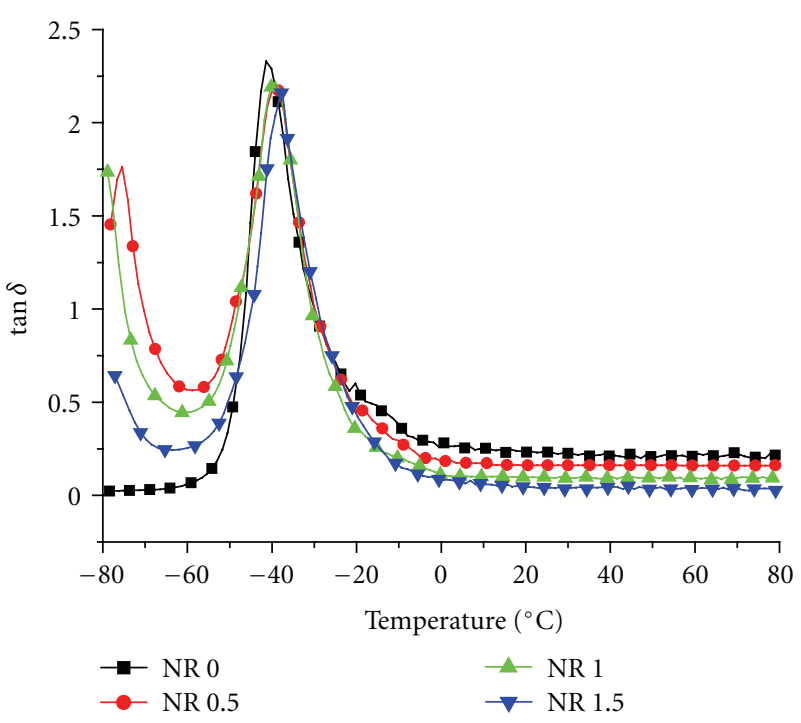

Figure 5: Dependences of mechanical loss angle tangent on temperature and filler amount.

presents the dependences of the tangent of mechanical loss angle $(\tan \delta)$ on temperature for the composites based on the studied rubber compounds filled with different amounts of fullerene. As the figure shows, at temperatures over $0^{\circ} \mathrm{C}$ there are no significant differences in $\tan \delta$ values dependent on the amount of the filler used. However, it could be stated that there is some decrease in $\tan \delta$ values with the increasing fullerene amount which is more visible in the $-20^{\circ} \mathrm{C} \sim$ $80^{\circ} \mathrm{C}$ range. It is known the $\tan \delta$ peak to correspond to the glass transition temperature $\left(T_{g}\right)$ of the composites. Figure 5 presents a slight decrease of $\tan \delta$ peak with the increasing filler concentration. Obviously that is due to the lower mobility of the macromolecules in the fullerene presence which is on account of their being adsorbed on the filler's surface. Moreover, at higher filler amounts, that peak is slightly shifted to the higher temperatures. Currently tire manufacturers use the dynamic mechanical thermal analysis to handle tire performance (wet grip, rolling resistance, etc.). It is recognized as a highly informative characterization technique implemented in industrial testing and in research and development. It is known that at 50$70^{\circ} \mathrm{C}$ the tangent of mechanical loss angle [17] correlates well with the rolling resistance which is an important parameter for the compounds designed for tire treads. The lower $\tan \delta$ value corresponds to lower rolling resistance [18]. On the other hand lower rolling resistance is a prerequisite of less fuel combustion and less environmental pollution [19]. As Figure 5 shows, at $70^{\circ} \mathrm{C}$ the increase in fullerene amount causes a decrease of $\tan \delta$ values. That allows the assumption that the introduction of small fullerene amounts into the compounds for summer tire treads would have a favourable impact upon their exploitation characteristics.

3.5. Dielectric Properties of the Vulcanizates Studied. Figures 6 and 7 present the frequency dependence of dielectric permittivity at different degree of fullerene filling, at $30^{\circ} \mathrm{C}$ and $90^{\circ} \mathrm{C}$, respectively. 


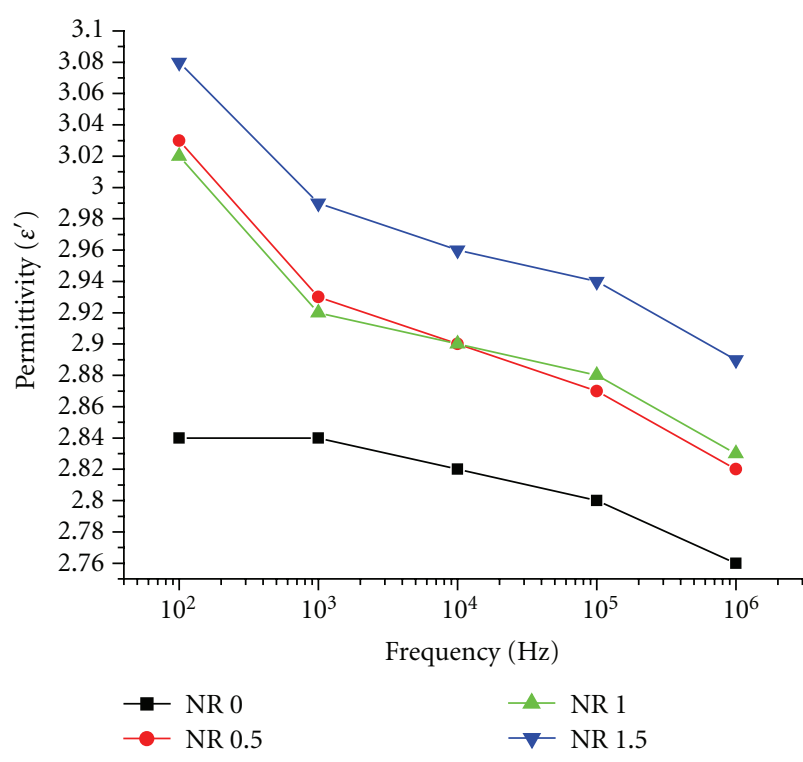

Figure 6: Frequency dependence of dielectric permittivity at different degree of fullerene filling, at $30^{\circ} \mathrm{C}$.

As seen from Figure 6 the values of dielectric permittivity $\varepsilon^{\prime}$ for filler loadings $0,5 \mathrm{phr}$ and $1,0 \mathrm{phr}$ samples are very close (the filler quantity is still very small). Only when the filler loading is $1,5 \mathrm{phr}$ the increasing of $\varepsilon^{\prime}$ may be observed. The plot shows that the dielectric permittivity of the composites decreases when the frequency increases. This fact is related to the rubber macromolecules polarization at higher frequency. The polarization mechanism operating in the gigahertz frequency is purely electronic or orientational with relaxation times smaller than the time period of the applied signals. Interfacial polarization, which is the basic reason for the dispersion in dielectric permittivity at radio frequency regime, has no role to play in microwave frequencies as it does not produce dispersion in $\varepsilon^{\prime}$ because of its much smaller relaxation time.

Figure 7 demonstrates that at $90^{\circ} \mathrm{C}$ the dependence of $\varepsilon^{\prime}$ on frequency and filler amount has the same tendency as the one at $30^{\circ} \mathrm{C}$ but at lower values. Both in case of filled and nonfilled composites the dependency curves have the same pattern, though in the first case the effect of the frequency is more pronounced.

DETA $\tan \delta$ values for the filled composites that we have measured at $30^{\circ} \mathrm{C}$ and $90^{\circ} \mathrm{C}$ are close to those for the nonfilled ones and are about $10^{-3}$, typical of the polymers possessing dielectric properties (Figures 8 and 9). However, as seen at higher filler amounts DETA $\tan \delta$ values increase. As a whole, DETA $\tan \delta$ values decrease with the increasing temperature. Noteworthy is the fact that at $30^{\circ} \mathrm{C}$ those values get higher at higher frequencies while at $90^{\circ} \mathrm{C}$ the tendency is reversed the higher the frequency the lower are DETA $\tan \delta$ values. The reason for the effects observed is the temperature influence on the relaxation dynamics of the macromolecular chains, especially on the intermolecular cooperative motion. As a result the times of relaxation change with the temperature: at higher temperature

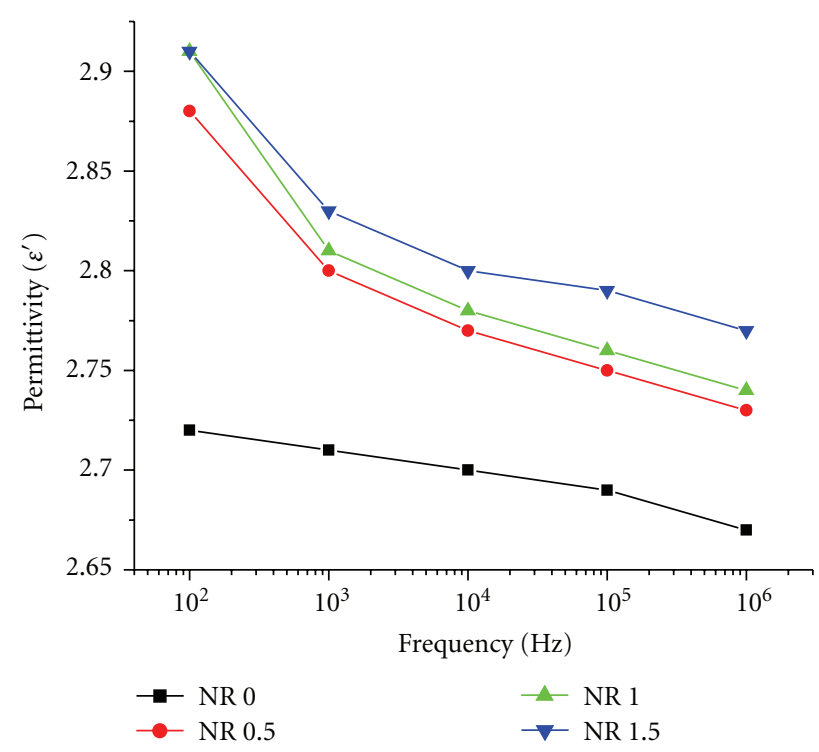

Figure 7: Frequency dependence of dielectric permittivity at a different degree of fullerene filling at $90^{\circ} \mathrm{C}$.

the relaxation times decrease, and this is the reason for DETA $\tan \delta$ decreasing.

\section{Conclusions}

It has been found that the presence of fullerene and its increasing amount prolongs the induction period and optimal vulcanization time, that is, fullerene retards the vulcanization process.

The presence of fullerene and its increasing amount increases the values of $M_{100}$ and $M_{300}$ and Shore A hardness while the tensile strength decreases. The relative elongation passes through a maximum and also starts decreasing after that.

The use of fullerene as filler in the rubber composites leads to an improvement of their thermal aging resistance.

The observed effects on the vulcanization process and on thermal aging resistance are assigned to fullerene ability to absorb free radicals which are of great importance both for the vulcanization process and for thermal aging resistance.

The dependence of the storage modulus and mechanical loss angle tangent on temperature and fullerene amount of the composites has been determined by DMTA investigations. It has been established that the transition from the glassy into the high-elastic state takes place at about $-50^{\circ} \mathrm{C}$. The increasing fullerene amount lowers the intensity of the peak $\tan \delta$ versus temperature and shifts the peak to lower temperatures. The effect is on account of the low mobility of the macromolecules caused by fullerene presence. In the high-elastic state temperature range the increase in temperature and in fullerene amount leads to a decrease of the mechanical loss angle tangent values.

The dielectric permittivity and dielectric loss angle tangent as a function of temperature and filler amount have been studied by DETA. It has been found that the increase in 


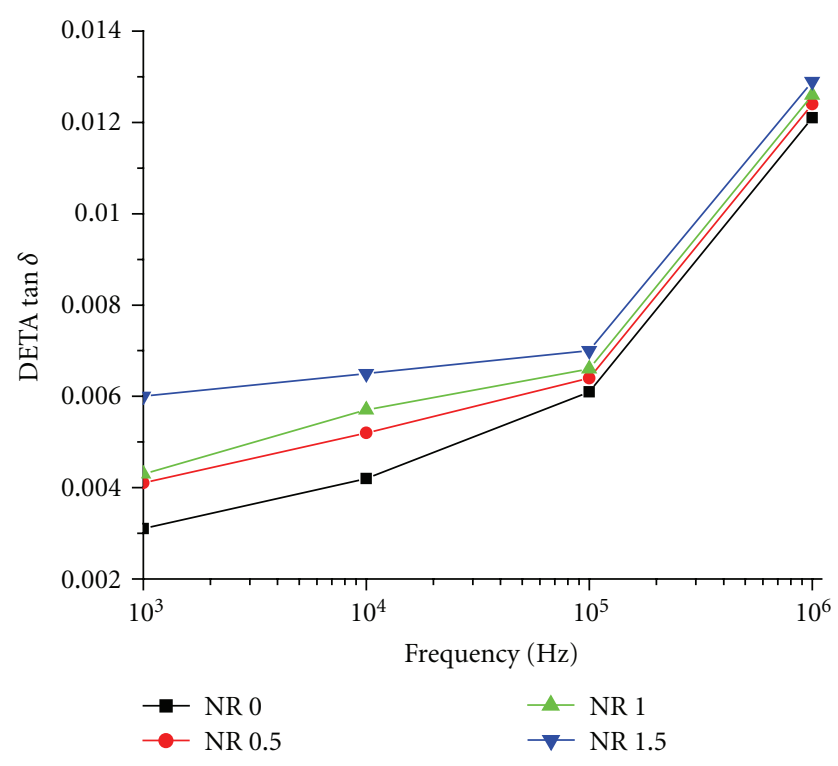

Figure 8: Frequency dependence of DETA $\tan \delta$ at a different degree of fullerene filling at $30^{\circ} \mathrm{C}$.

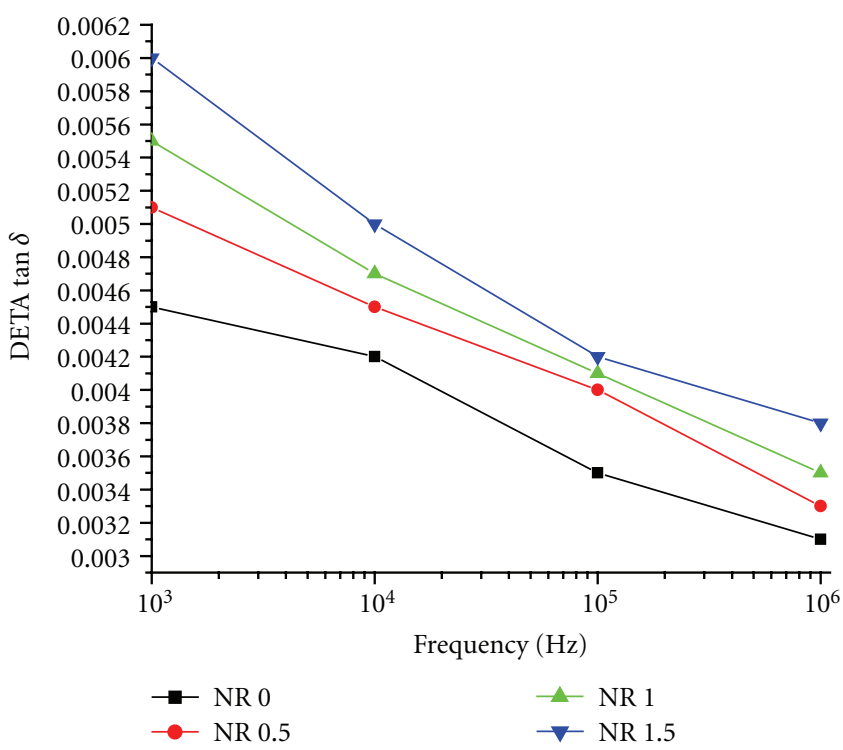

FIGURE 9: Frequency dependence of DETA $\tan \delta$ at a different degree of fullerene filling at $90^{\circ} \mathrm{C}$.

fullerene amount increases the values of DETA $\tan \delta$, while at higher temperatures those values get lower.

\section{Acknowledgments}

The present research is a result of an international collaboration program between University of Tabuk, Tabuk, Saudi Arabia and the University of Chemical Technology and Metallurgy, Sofia, Bulgaria. The authors gratefully acknowledge the financial support from the University of Tabuk.

\section{References}

[1] H. Murayama, S. Tomonoh, J. M. Alford, and M. E. Karpuk, "Fullerene production in tons and more: from science to industry," Fullerenes Nanotubes and Carbon Nanostructures, vol. 12, no. 1-2, pp. 1-9, 2004.

[2] H. W. Kroto, J. R. Heath, S. C. O'Brien, R. F. Curl, and R. E. Smalley, "C60: buckminsterfullerene," Nature, vol. 318, no. 6042, pp. 162-163, 1985.

[3] S. Thomas and R. Stephen, Rubber Nanocomposites Preparation, Properties and Applications, Wiley, Singapore, 2010.

[4] P. R. Birkett, P. B. Hitchcock, H. W. Kroto, R. Taylor, and D. R. M. Walton, "Preparation and characterization of $\mathrm{C}_{60} \mathrm{Br}_{6}$ and $\mathrm{C}_{60} \mathrm{Br}_{8}$," Nature, vol. 357, no. 6378, pp. 479-481, 1992.

[5] B. C. Yadav and R. Kumar, "Structure, properties and applications of fullerene," International Journal of Nanotechnology and Applications, vol. 2, no. 1, pp. 15-24, 2008.

[6] L. Chow, "CVD method of producing and doping fullerenes," US Pat, 5510 098, 1996.

[7] B. Jurkowska, B. Jurkowski, P. Kamrowski et al., "Properties of fullerene-containing natural rubber," Journal of Applied Polymer Science, vol. 100, no. 1, pp. 390-398, 2006.

[8] L. Zhao, P. Song, Z. Cao, Z. Fang, and Z. Guo, "Thermal stability and rheological behaviors of high-density polyethylene/fullerene nanocomposites," Journal of Nanomaterials, vol. 2012, Article ID 340962, 6 pages, 2012.

[9] E. V. Chubarova and E. Y. Melenevskaya, "Chain degradation during dissolution of polymer-fullerene nanocomposites as a result of interaction of entangled polymer matrix with the filler," Journal of Macromolecular Science B, vol. 49, no. 1, pp. 174-206, 2010.

[10] E. Badamshina and M. Gafurova, "Polymeric nanocomposites containing non-covalently bonded fullerene C60: properties and applications," Journal of Materials Chemistry, vol. 22, pp. 9427-9438, 2012.

[11] M. Putman, "Review of dispersion methods and the relationships of dispersion to physical properties," Tire Technology International, Annual Review, pp. 52-54, 2008.

[12] A. R. Payne, "Effect of dispersion on the properties of fillerloaded rubbers," Journal of Applied Polymer Science, vol. 9, no. 6, pp. 2273-2284, 1965.

[13] J. S. Dick, Rubber Technology-Compounding and Testing for Performance, Carl Hanser, Munich, Germany, 2001.

[14] J. E. Mark, B. Erman, and F. E. Eirich, The Science and Technology of Rubber, Elsevier, Amsterdam, The Netherlands, 3rd edition, 2005.

[15] G. Scott, Atmospheric Oxidation and Antioxidants, Elsevier, Amsterdam, The Netherlands, 1975.

[16] P. Elmer, Introduction to DMTA (A Beginner's Guide).

[17] J. B. Donnet, "Nano and microcomposites of polymers elastomers and their reinforcement," Composites Science and Technology, vol. 63, no. 8, pp. 1085-1088, 2003.

[18] H. Baurier, "Dynamic mechanical analysis to improve tire performance," Tire Technology International, Annual Review, pp. 116-119, 2008.

[19] J. Neubauer, "Improving key tire performance," Tire Technology International, Annual Review, pp. 10-12, 2009. 

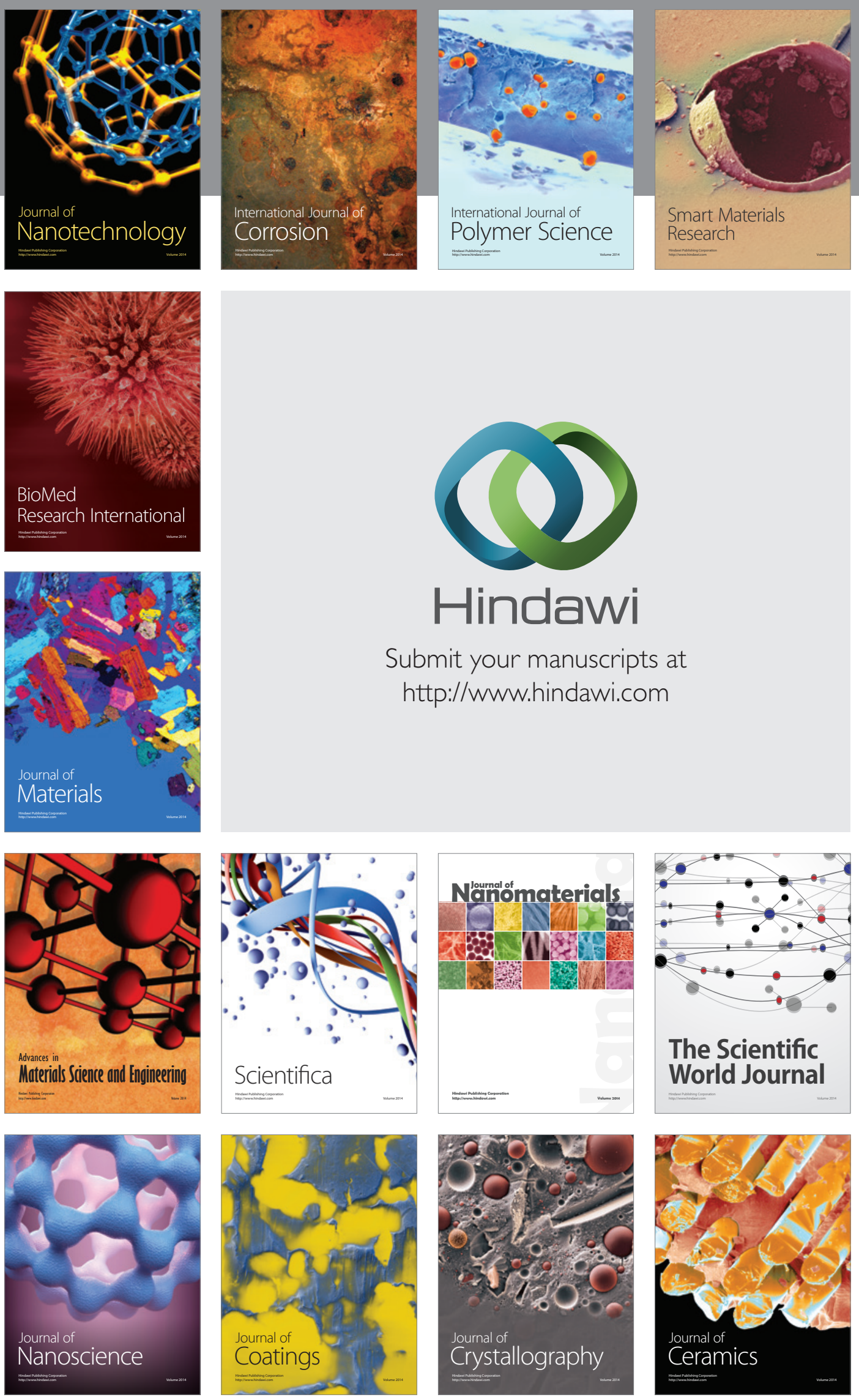

The Scientific World Journal

Submit your manuscripts at

http://www.hindawi.com

\section{World Journal}

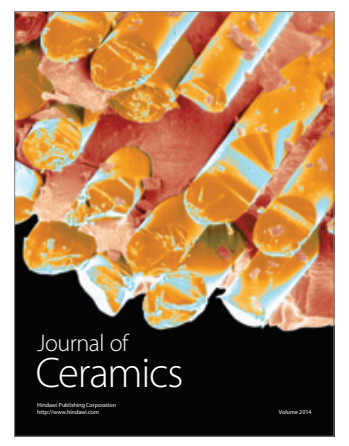

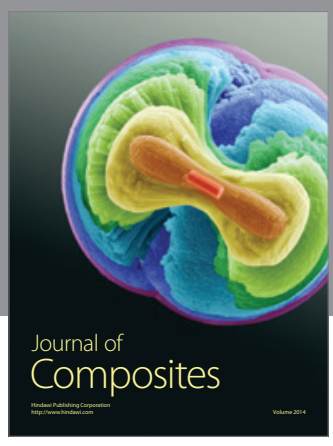
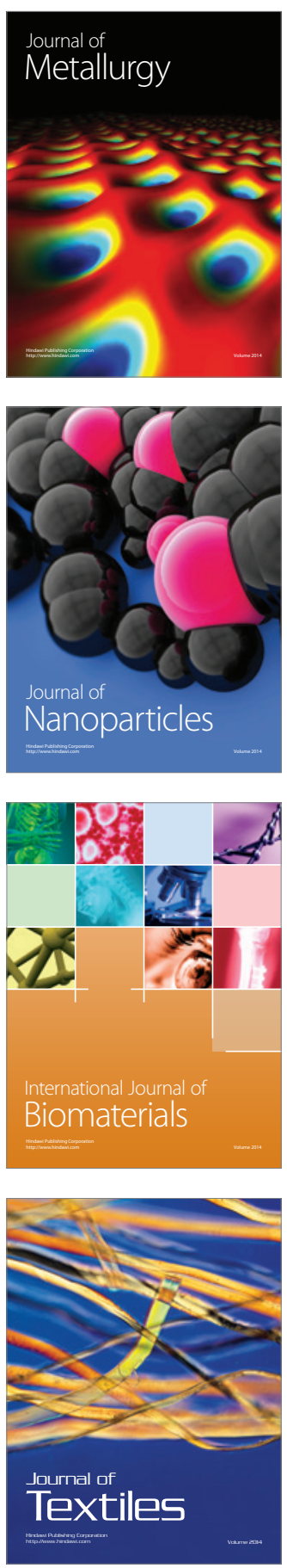